\title{
Analysis on the Utilization of Foreign Direct Investment in the Minority Provinces of China
}

\author{
Liu Xiuling, Zhu Ruixue*, Cai Li \\ International Business School, Dalian Minzu University, Dalian, China \\ *Corresponding author: oh-snow@dlnu.edu.cn
}

\begin{abstract}
Although the economy of China's minority provinces have developed very fast in recent years, the scale of their foreign direct investment(FDI) is relatively small. In-depth analysis on the utilization of FDI in the minority provinces can help thoroughly understand their weakness and problems, which is helpful for taking countermeasures accordingly to improve the scale and level of minority provinces' utilization of FDI.
\end{abstract}

Keywords: minority provinces, FDI, investment environment, growth pole

Cite This Article: Liu Xiuling, Zhu Ruixue, and Cai Li, "Analysis on the Utilization of Foreign Direct Investment in the Minority Provinces of China." International Journal of Econometrics and Financial Management, vol. 5, no. 2 (2017): 37-41. doi: 10.12691/ijefm-5-2-3.

\section{Introduction}

The economic development of China's minority provinces needs a large amount of capital. Since the capital formation in China's minority provinces is difficult, the utilization of FDI is beneficial for them to accumulate capitals, exploit their resource advantages, improve their industrial structures and promote their economic system reform, which are important for the economic development of those regions [1].

FDI contributes to regional economic complexity, which is considered to be an important factor for promoting economic growth and improving regional sustainable competitiveness under current complicated economic circumstances. Recent studies show that economic complexity has close relationship with economic growth [2]. Greater economic complexity and deeper production diversification can lead to stronger ability of economic sustainable development. Specifically economic complexity depends on the diversification of industries, capital owners, commodities, technologies, competitions, etc. Thus FDI is one of the important factors that contribute to economic complexity. In fact, globalization of multinational companies and global flow of capitals have become important driving forces for the economic growth in developing countries.

FDI led to the formation of industrial clusters in the eastern coastal regions of China and has become an engine of China's economic development. According to the statistics of the Ministry of Commerce of China, the cumulative absorption of FDI amounted to 1655.95 billion U.S. dollars and the number of foreign investment companies reached 128953 by the end of 2015 in China.

Although the economic development of China's minority provinces (which refer to Ningxia, Inner Mongolia, Guangxi, Tibet, Xinjiang, Guizhou, Yunnan and Qinghai in this paper), located in the western part of China, are fast in recent years, the scale of their FDI is relatively small and the level is low. Although the proportion of the actual utilization of FDI by the eight minority provinces has risen from 1.20 percent in 1988 to 7.63 percent in 2015 in China (see Table 1), their land and population accounts for 69 percent and 25 percent of China respectively. Capitals and technologies are key to speed up the economic development of minority provinces. On the basis of the strengthening of the financial support from the state and the assistance from the eastern regions of China, the expansion of FDI scale and the improvement of FDI performance can speed up the economic development of the minority provinces.

Table 1. The Utilization of FDI in Minority Provinces (2015) (billions of USD, \%)

\begin{tabular}{|l|c|c|c|}
\hline & $\begin{array}{c}\text { Amount of } \\
\text { FDI }\end{array}$ & $\begin{array}{c}\text { Year-on-year } \\
\text { growth rate }\end{array}$ & $\begin{array}{c}\text { Ratio of the } \\
\text { province to the } \\
\text { country }\end{array}$ \\
\hline Nationwide & 1262.7 & 6.4 & 100 \\
\hline $\begin{array}{l}\text { Minority } \\
\text { provinces in total }\end{array}$ & 96.35 & 112.8 & 7.63 \\
\hline Inner Mongolia & 33.7 & -15.4 & 2.67 \\
\hline Xinjiang & 4.53 & 8.5 & 0.36 \\
\hline Guangxi & 17.22 & 72 & 1.36 \\
\hline Yunnan & 29.9 & 10.6 & 2.37 \\
\hline Qinghai & 0.55 & 9.8 & 0.04 \\
\hline Guizhou & 5.69 & 22.2 & 0.45 \\
\hline Ningxia & 3.81 & 45.4 & 0.3 \\
\hline Tibet & 0.95 & -40.3 & 0.08 \\
\hline
\end{tabular}

Source: Bureau of Statistics of Minority provinces of China, Statistical Yearbook of China (2016). 


\section{Characteristics of the Utilization of FDI in Minority Provinces}

\subsection{The Proportion of FDI of Minority Provinces in China is Very Low}

Table 2 lists the amount of FDI in minority provinces and its proportion in China during the period from 1990 to 2015. Although the amount of FDI in minority provinces has been on the increase from just 56 million dollars in 1990 to 9.6 billion dollars in 2015 , its proportion in China's overall amount of FDI only increased from 0.55 percent in 1999 to 7.63 percent in 2015 .

Table 2. The Proportion of FDI of Minority Provinces in China (1991-2015) (billions of USD, \%)

\begin{tabular}{|c|c|c|c|}
\hline Year & $\begin{array}{l}\text { Amount of FDI of } \\
\text { minority provinces }\end{array}$ & Nationwide & Ratio \\
\hline 1990 & 0.5633 & 102.89 & 0.55 \\
\hline 1991 & 0.9199 & 115.54 & 0.80 \\
\hline 1992 & 2.4487 & 192.03 & 1.28 \\
\hline 1993 & 11.668 & 389.60 & 2.99 \\
\hline 1994 & 13.046 & 432.13 & 3.02 \\
\hline 1995 & 11.671 & 481.33 & 2.42 \\
\hline 1996 & 10.376 & 548.05 & 1.89 \\
\hline 1997 & 12.367 & 644.08 & 1.92 \\
\hline 1998 & 12.478 & 585.57 & 2.13 \\
\hline 1999 & 9.841 & 526.59 & 1.87 \\
\hline 2000 & 8.753 & 593.56 & 1.47 \\
\hline 2001 & 6.788 & 496.72 & 1.37 \\
\hline 2002 & 9.731 & 550.11 & 1.77 \\
\hline 2003 & 13.114 & 561.40 & 2.34 \\
\hline 2004 & 14.678 & 640.72 & 2.29 \\
\hline 2005 & 22.262 & 638.05 & 3.49 \\
\hline 2006 & 30.382 & 670.76 & 4.53 \\
\hline 2007 & 38.634 & 783.39 & 4.93 \\
\hline 2008 & 50.433 & 952.53 & 5.29 \\
\hline 2009 & 56.399 & 918.04 & 6.14 \\
\hline 2010 & 64.830 & 1057.35 & 6.13 \\
\hline 2011 & 78.756 & 1160.11 & 6.79 \\
\hline 2012 & 83.778 & 1117.16 & 7.50 \\
\hline 2013 & 92.606 & 1175.86 & 7.86 \\
\hline 2014 & 88.684 & 1195.60 & 7.41 \\
\hline 2015 & 96.350 & 1262.70 & 7.63 \\
\hline
\end{tabular}

Source: Bureau of Statistics of Minority provinces, National Bureau of Statistics of China, Statistical Yearbook of China.

\subsection{The Source of FDI in Minority Provinces is in Accordance with the Country}

In terms of the investor origins, the FDI sources of the minority provinces tend to be consistent with the country.
By the end of 2014, the accumulative amount of FDI in the mainland of China from Hong Kong reached 746.9 billion U.S. dollars, which ranked number one and took up 49.3 percent of the total FDI of the mainland. In 2014, the investment from Hong Kong in the mainland took up 68 percent of total FDI (see Table 3). Thus Hong Kong is the biggest FDI source of China. As shown in Table 3, the investment from Hong Kong took up 73.2 percent, 54 percent, 48.2 percent, 49.2 percent of the total FDI respectively in Yunnan, Guangxi, Qinghai and Ningxia provinces in 2014, which all ranked number one in the four provinces. It can be seen that the investment from Hong Kong is much higher in Yunnan province than the country, and lower in Guangxi, Qinghai and Ningxia than the country. The second biggest FDI source for those minority provinces is Singapore (except for Yunnan, whose second biggest FDI source is Germany), which is also in accordance with the country.

Table 3. Top Two FDI Sources in Yunnan, Guangxi, Qinghai and Ningxia (2014) (millions of USD, \%)

\begin{tabular}{|c|c|c|c|c|}
\hline \multirow{2}{*}{ FDI source } & \multicolumn{2}{|c|}{ Hong Kong } & \multicolumn{2}{c|}{ Singapore } \\
\cline { 2 - 5 } & value & ratio & value & ratio \\
\hline Yunnan & 1,982 & 73.2 & 27.8 (Germany) & 10.3 \\
\hline Guangxi & 540.2 & 54 & 11.05 & 11 \\
\hline Qinghai & 51.28 & 48.2 & 46.65 & 37.6 \\
\hline Ningxia & 45.51 & 49.2 & 20.41 & 22.1 \\
\hline Nationwide & 81320 & 68 & 59300 & 20.2 \\
\hline
\end{tabular}

Source: Bureau of Statistics of Minority provinces, National Bureau of Statistics of China, Statistical Yearbook of China (2015).

\subsection{The Forms of FDI in Minority Provinces are Different from the Country}

In terms of the forms of FDI, the proportion of wholly foreign-owned enterprises is the largest in Yunnan, Guangxi and Xinjiang, which is in line with the country. As shown in Table 4, the proportion of wholly foreign-owned enterprises in Guangxi and Yunnan accounted for above 50 percent in 2014 . But compared with the country, the proportion was still much lower. Furthermore, since many foreign investors bought shares of local resource-based enterprises, the proportion of FDI shareholding incorporations in Inner Mongolia and Xinjiang, which were 49.7 percent and 34.8 percent respectively in 2014 , was much larger than the average level of the country.

\subsection{The Regional Distribution of FDI in Minority Provinces is Imbalanced}

Inner Mongolia, Yunnan and Guangxi has been the top three provinces in utilizing FDI, and the proportion of the FDI utilized by the three provinces has always been above 80 percent of the total FDI of the minority provinces (see Table 5). The proportion of the rest five minority provinces is very low. So the regional distribution of FDI in minority provinces is imbalanced. The proportion of FDI keeps on increasing in Inner Mongolia and Yunnan, and declining in Guangxi. 
Table 4. The Forms of FDI in Inner Mongolia, Yunnan, Guangxi and Xinjiang (2014) (millions of USD, \%)

\begin{tabular}{|c|c|c|c|c|c|c|c|c|c|c|}
\hline \multirow{2}{*}{$\begin{array}{l}\text { Region } \\
\text { Index }\end{array}$} & \multicolumn{2}{|c|}{ Inner Mongolia } & \multicolumn{2}{|c|}{ Yunnan } & \multicolumn{2}{|c|}{ Guangxi } & \multicolumn{2}{|c|}{ Xinjiang } & \multicolumn{2}{|c|}{ Nationwide(total of 2002-2012) } \\
\hline & value & ratio & value & ratio & value & ratio & value & ratio & value & ratio \\
\hline Total & 3977 & 100 & 2706 & 100 & 1001 & 100 & 417 & 100 & 864720 & 100 \\
\hline Wholly foreign- owned enterprises & 795 & 20.0 & 1504 & 55.6 & 651 & 65.0 & 156 & 37.4 & 635430 & 73.4 \\
\hline Equity joint venture & 1205 & 30.3 & 515 & 19.0 & 350 & 35.0 & 115 & 27.5 & 192030 & 22.3 \\
\hline Contractual joint venture & 0 & 0 & 361 & 13.4 & 0 & 0 & 1.2 & 0.3 & 26860 & 3.1 \\
\hline FDI shareholding Inc. & 1978 & 49.7 & 325 & 12.0 & 0 & 0 & 145 & 34.8 & 10400 & 1.2 \\
\hline
\end{tabular}

Source: Bureau of Statistics of Minority provinces, Report on Foreign Investment in China (2013).

Table 5. Five-year Sum of FDI in Minority Provinces (1991-2015) (USD 10, 000,\%)

\begin{tabular}{|c|c|c|c|c|c|c|c|c|c|c|}
\hline Period & \multicolumn{2}{|c|}{$1991-1995$} & \multicolumn{2}{|c|}{$1996-2000$} & \multicolumn{2}{|c|}{$2001-2005$} & \multicolumn{2}{|c|}{$2006-2010$} & \multicolumn{2}{c|}{$2011-2015$} \\
\hline Index & value & ratio & value & ratio & value & ratio & value & ratio & value & ratio \\
\hline Inner Mongolia & 31020 & 7.80 & 43625 & 8.11 & 251802 & 37.82 & 1290870 & 53.63 & 1977400 & 46.71 \\
\hline Yunnan & 55111 & 13.86 & 77265 & 14.36 & 65879 & 9.90 & 371287 & 15.43 & 1053720 & 24.89 \\
\hline Guangxi & 257558 & 64.79 & 359413 & 66.79 & 193205 & 29.02 & 404988 & 16.83 & 518561 & 12.25 \\
\hline Xinjiang & 21896 & 5.51 & 15620 & 2.90 & 19709 & 2.96 & 87146 & 3.62 & 200940 & 4.75 \\
\hline Ningxia & 9745 & 2.45 & 6650 & 1.24 & 20451 & 3.07 & 30080 & 1.25 & 104560 & 2.47 \\
\hline Tibet & & 0 & - & 0 & - & 0 & 18622 & 0.77 & 59300 & 1.40 \\
\hline Qinghai & 3133 & 0.798 & 16331 & 3.03 & 85233 & 12.80 & 123930 & 5.15 & 57381 & 1.36 \\
\hline Guizhou & 19073 & 4.80 & 19241 & 3.58 & 29456 & 4.42 & 79849 & 3.32 & 261800 & 6.18 \\
\hline Total & 347936 & 100 & 538145 & 100 & 665735 & 100 & 2406772 & 100 & 4233662 & 100 \\
\hline
\end{tabular}

Source: Bureau of Statistics of Minority provinces, Statistical Bulletin on Economic and Social Development (2015).

Table 6. Industrial Distribution of FDI in Inner Mongolia, Yunnan, Guangxi and Xinjiang (2014) (USD10, 000, \%)

\begin{tabular}{|c|c|c|c|c|c|c|c|c|c|}
\hline \multicolumn{2}{|c|}{ Sector } & \multirow{2}{*}{$\begin{array}{c}\begin{array}{c}\text { Agriculture, forestry, } \\
\text { animal husbandry and } \\
\text { fishery }\end{array} \\
51921\end{array}$} & \multirow{2}{*}{$\begin{array}{l}\text { Mining } \\
171035\end{array}$} & \multirow{2}{*}{$\begin{array}{c}\text { Manufacturing } \\
107725\end{array}$} & \multirow{2}{*}{$\begin{array}{c}\text { Construction } \\
-\end{array}$} & \multirow{2}{*}{$\begin{array}{l}\begin{array}{c}\text { Real } \\
\text { estate }\end{array} \\
2100\end{array}$} & \multirow{2}{*}{$\begin{array}{c}\begin{array}{c}\text { Leasing and } \\
\text { Business } \\
\text { Services }\end{array} \\
31668\end{array}$} & \multirow{2}{*}{$\begin{array}{c}\begin{array}{c}\text { Transport } \\
\text { and } \\
\text { Storage }\end{array} \\
18384\end{array}$} & \multirow{2}{*}{$\begin{array}{c}\text { Total } \\
397748\end{array}$} \\
\hline Inner & value & & & & & & & & \\
\hline Mongolia & ratio & 13.1 & 43.0 & 27.1 & - & 0.53 & 8.0 & 4.62 & 100 \\
\hline \multirow{2}{*}{ Yunnan } & value & 2100 & 4900 & 78400 & 9200 & 94600 & 52200 & $\longrightarrow$ & 270600 \\
\hline & ratio & 0.78 & 1.81 & 29.0 & 3.40 & 35.0 & 19.3 & - & 100 \\
\hline \multirow{2}{*}{ Guangxi } & value & 310 & - & 44552 & - & 40673 & - & 2263 & 100119 \\
\hline & ratio & 0.3 & - & 44.5 & - & 40.6 & - & 2.3 & 100 \\
\hline \multirow{2}{*}{ Xinjiang } & value & 475 & 2812 & 18453 & 7 & 544 & 13 & 14341 & 41700 \\
\hline & ratio & 1.14 & 6.74 & 44.3 & 0.02 & 1.30 & 0.3 & 34.4 & 100 \\
\hline
\end{tabular}

Source: Bureau of Statistics of Minority provinces, National Bureau of Statistics of China, Statistical Yearbook of China (2015).

\subsection{The Industrial Structures of FDI in Minority Provinces are Unreasonable}

Not only the amount of FDI and the number of foreign enterprises is relatively small in minority provinces, the industrial structures of their FDI is unreasonable. FDI in minority provinces is mainly distributed in processing and manufacturing industries, especially in low-tech, low value-added and rough machining industries, e.g. resource-intensive industries and labor-intensive industries. FDI invested in technology-intensive and capital-intensive industries is few. FDI invested in agriculture, infrastructure and producer service industries is also very few (see Table 6).

\section{Countermeasures for Improving FDI Utilization in Minority Provinces}

Minority provinces of China are located in the core regions of the Silk Road Economic Belt and the 21st Century Maritime Silk Road, and they are the key nodes and key hubs of "connectivity". "One Belt One Road" initiative provides unprecedented opportunities for the leap-forward development of the minority provinces and it will profoundly change their development orientation and greatly improve their investment environment. Minority provinces need to overcome many difficulties, e.g. their market system is undeveloped, non-state economic sectors are not enough, their economic foundation is still weak, 
their technology and education level is low, etc. Minority provinces should catch the opportunities brought by the "One Belt One Road" initiative, bring their superiority into full play, improve their investment environment, attract high quality FDI, and speed up the development of open economy.

\subsection{To Strengthen the Building of Soft Investment Environment in Minority Provinces}

How much of the FDI's driving effects of job creation, entrepreneurship encouragement, innovation ability cultivation on the host countries (regions) can be turned into reality is closely related to the specific policies of attracting FDI by the local government. Minority provinces should give full play to the advantages of combination of government domination and market incentives, formulate feasible policies and measures, build sound market, legal and social environment for the FDI from the aspects of taxation, finance, government services, etc.

\subsection{To Choose the "Growth Poles" That Appeal to FDI}

Minority provinces need to set up competitive FDI-attracting strategies and choose regional "growth poles" that appeal to FDI.

\subsubsection{To Attract FDI by Building Sound Investment Environment of Industrial Parks}

The industrial chains of the minority provinces are usually not outward-looking, their international market competitiveness is weak and they haven't formed positive interaction with FDI. It is appropriate for the minority provinces to choose "pole-axis" development mode, cultivate sources of regional economic growth with strong radiation force and leading roles, and promote sound interaction between FDI and the economic development of minority provinces. Industrial parks will be the main way for the western minority regions to achieve industrial clustering, which has been well proved by the current development of industrial parks in foreign countries and China's eastern regions [3]. State-level industrial parks and province-level industrial parks with better conditions should be first chosen to strengthen attracting FDI, improve business environment and form industry clustering effects, and then more areas can be extended to do so.

\subsubsection{To Play the Leading Roles of the Core Cities}

Minority provinces should focus on nurturing and strengthening some important economic zones, which are based on core cities and have strong bearing capacity and great development potentials, reasonably adjust industry distribution, promote industrial clusters, and improve their radiation ability [4]. On the basis of the current megacities and advanced industrial bases, minority provinces should build their own economic development mode conforming to local situations.

\subsection{To Vigorously Develop Modern Service Industry Clusters}

Since China's reform and opening up, China's eastern coastal regions' policies of attracting FDI is opening the manufacturing industries first and then the service industries. Minority provinces can choose different opening order according to their own conditions and current situations. For example, minority provinces may choose to open service industries first to attract FDI flow into it, through which it can accelerate the improvement of service environment of the minority regions, thus to appeal to more high-quality FDI [5]. Therefore minority provinces should first strengthen the building of logistics and information platform based on their hub infrastructures which are located along the oceans, rivers and boarders, strongly develop brand logistics enterprises, and support the development of major logistics enterprises which have sound foundations and competitiveness. Minority provinces should promote the formation of a unified open logistics market through strategic alliances and multi-modal transport logistics network system. Second, minority provinces should develop a group of information industries focusing on e-commerce, convention and exhibition, information consultancy, distance education, telemedicine, etc. Traditional industries should be transformed by widely using information technology. Online sales, chain operations, credit consumption and other new types of marketing and service modes should be vigorously promoted and their service quality and operation performance should also be improved. Modern business system, which is well arranged, has reasonable commercial forms and multiple functions, and links urban areas and countryside should be established. Third, minority provinces should speed up the development of culture industries, especially ethic culture industries.

\subsection{To Strongly Develop Low-Carbon Industry Clusters}

Most of the minority provinces are resource-intensive regions, thus they should deal well with resource and environment problems. They should remove the resource and environmental constraints fundamentally for the future sustainable development of their industries and promote the development of low-carbon industries. Certain industry clusters could be chosen by the minority provinces to be the pilots of circular economy. Cyclic utilization network of matter and energy within industry agglomeration should be established, and circular economy and ecological industries should be developed. The Clean Production Promotion Act and Energy Conservation Law, etc. should be implemented. Through clean production, energy conservation, pollution control and elimination of backward production capacity, energyintensive and high pollution industries will be converted into energy conservation and environmentally friendly industries. Minority provinces should also strengthen the recycling of waste materials, explore centralized treatment for the industry agglomerations which have large amount of refuse discharge and heavy pollution. Energy saving and emission reduction technology should be popularized to reduce enterprises' pollution control cost. 


\section{Conclusion}

Although the economy of China's minority provinces have developed very fast in recent years, the scale of their FDI is relatively small and has taken on certain characteristics, e.g. the proportion of FDI of minority provinces in china is very low, its source is in accordance with the country, but its forms are different from the country, its regional distribution is imbalanced and its industrial structures are unreasonable. "One Belt One Road" initiative provides unprecedented opportunities for the leap-forward development of the minority provinces. In order to seize the opportunities and attract more high quality FDI, the minority provinces need to strengthen the building of soft investment environment, choose the "growth poles" that appeal to FDI, vigorously develop modern service industry clusters, and strongly develop low-carbon industry clusters.

\section{Acknowledgements}

This research is supported by the National Social Science Foundation of China (11BMZ043) and the
Fundamental Research Funds for the Central Universities of China (20150210, 20150425, 20150426).

\section{References}

[1] Yang Haiyan, Gu Xiaoyan, Ju Jingiiang, Utilization of foreign capital and capital formation in minority areas, Inner Mongolia Social Sciences (Chinese version), 9(10). 31-32. Sep. 2005.

[2] Pin Xinqiao, Zhao Wei, Attracting FDI by ethnic minority areas: history, present situation and the reasons why they lag behind, Comparison Of Economic and Social System, 3(3).5-6. March.2014.

[3] Liu Xiuling, Miao Fang, Sun Xianfeng, Zhu Ruixue, Cai Li, FDI and the development of the characteristic export-oriented industrial clusters in minority regions, Journal of Dalian Minzu University, 2(2). 54-55. Feb. 2013.

[4] He Aihong, Thoughts on the utilization of foreign capital by minority regions, Journal of Northwest Minzu University (philosophy and social sciences), 4(12). 12-14. April. 2007.

[5] Zhang Jian, To actively utilize foreign capital to promote the development of minority areas, Financial Research, 10(22). 23-24. Oct. 2011. 